\title{
UN LIBRO PERDIDO DE BALTASAR GRACIAN
}

La portada y piezas preliminares del Oráculo manual y arte de prudencia (Huesca, 1647) legan a los comentadores dos problemas: el de la intervención de Lastanosa, y el de la relación con las obras del jesuíta -impresas o manuscritas, acabadas o esbozadas- que le sirvieron de cantera. La portada pregona que el arte de prudencia está "sacada de los aforismos que se discurren en las obras de Lorenço Gracián". La aprobación de fray Gabriel Hernández afirma: "veese aquí de una vez todas las obras deste autor"; la del doctor Juan Francisco Andrés precisa "obras impresas y manuscritas"; por último, el aviso Al lector -sin firma, pero que viene tras la dedicatoria firmada por Lastanosa- se ufana de "ofrecerte de un rasgo todos los doze Gracianes". Esta cifra de doce tratados la había ya fijado el año anterior don Manuel de Salinas en el soneto acróstico estampado al frente de $\mathrm{El}$ Discreto (Huesca, 1646). Flotan en el aire tres preguntas. ¿Es el Oráculo verdadera antología o refundición o elaboración? ¿De qué libros deriva? ¿Quién hizo la selección, Gracián o Lastanosa? La intervención de Lastanosa está afianzada por la portada ("publícala D. Vincencio luan de Lastanosa") y por la dedicatoria que lleva al final su nombre. ¿Se contentó con ser el mecenas que costeó la obra y sirvió de pararrayos contra las iras de la Orden, o se internó en los papeles del amigo para florear los aforismos más lucidos? Ricardo del Arco abultó la iniciativa de don Vincencio, al que convirtió en un verdadero colaborador. Miguel Romera-Navarro en su "edición crítica y comentada" del Oráculo manual y arte de prudencia (Madrid, 1954) terció con valentía en el debate, negando la intromisión de Lastanosa en la selección o redacción, y sosteniendo que los 300 aforismos no son un florilegio sino un libro nuevo.

Romera-Navarro no sólo arremete contra la participación de Lastanosa a título de antologista o retocador, sino que le niega, contra la opinión común, la paternidad de la dedicatoria y el aviso Al lector. Un minucioso cotejo de estos dos trechos con el estilo del Museo de las medallas (Huesca, 1645), obra genuina de don Vincencio, descubre tan radicales oposiciones, que la consecuencia plausible es atribuir la dedicatoria y la advertencia a la pluma de Gracián, respaldado tras la iniciativa de su protector contra las iras de sus superiores.

En cambio, su interpretación de los "doze Gracianes" parece bastante endeble. Los gracianistas, frente a las repetidas afirmaciones de aprobaciones, dedicatorias y elogios, habían concordado en que el Oráculo merecía el nombre de extracto o antología de Gracián. Quizá habían explicado con poca sutileza el entronque con los demás escritos, pero se

posee las de $1570,1574,1575,1598$ y 163\%. En la B. N. P. existe la de 1569 , y en la Colección Ticknor de la Boston Public Library, la de 1588 (sign. D.150a.12) y la de 1632 (sign. D.16oa.21). Falta localizar ejemplares de la importantísima ed. de 1564, la primera de esta familia, y de la ed. de 1577 (Sevilla, A. Picardo). Simón Díaz, loc. cit., y PALAU, Manual, s. $v$. "Manrique, Jorge", mencionan algunas otras ediciones de las Coplas sin indicar si incluyen también el Diálogo.-Como ejemplos del tipo de estudio que recomiendo, véase CuR'T F. BüHLER, "Studies in the early editions of the Fiore di virtu', PBSA, 49 (1955), 315-339, y "The earliest editions of Juvenal", StR, 2 (1955), 84-95. 
habian percatado de que el autor, al intercalar sus viejos aforismos, se tomaba la libertad de modificarlos. Maurice Lacoste, "Les sources de l'Oráculo manual", $B H i$, 31 (1929), p. 94, nos lo dirá bien claro: "Il ne semble pas que l'Oráculo... contienne donc aucune partie à proprement parler originale... Nous ne prétendons pas qu'aucun texte n'ait été remanié quand il a été inclus dans l'Oráculo... Un grand nombre de maximes ne sont composées que de phrases refaites, retouchées, adaptées à cette forme lapidaire... Ce n'est pas à proprement parler un recueil de morceaux choisis, mais plutôt un résumé de l'œuvre". Los eruditos, confrontando el Oráculo con los impresos de Gracián, apenas conseguian rastrear la procedencia de un breve número de aforismos. Por ello suponían que los restantes derivaban de las obras manuscritas, de las que sólo conocemos dos títulos: El Atento (o Avisos al varón atento), varias veces citado por el mismo autor, y El Galante, mencionado una sola vez en $E l$ Discreto. Lacoste había señalado (p. 10o) las máximas en que salen las voces atento y atención, imaginando que eran fragmentos del perdido tratado primero. Evaristo Correa Calderón, "Hipótesis sobre el Oráculo manual", $R F E, 28$ (1944), p. 67, se representa el Oráculo como "una selección doctrinal, condensada hasta lo indecible..., de sus obras anteriores"; aumenta el repertorio de máximas conjeturalmente derivadas de $E l$ Atento y supone se podría seguir el rastro a los relieves de El Galante; con todo, no se aventura a la empresa, a todas luces más difícil.

Romera-Navarro arranca contra los ingenuos estudiosos que han aceptado por su valor literal la afirmación terminante de que el Oráculo era una quintaesencia de los doce Gracianes, y encabeza el apartado 4 de su prólogo con el epígrafe: "El Oráculo, libro nuevo, no una recopilación". Subraya la novedad de su posición continuando: "Que no hayan negado los eruditos, o puesto en duda siquiera, que el Oráculo sea una antología o recopilación, parecerá inexplicable" (p. xxv). Lo que sigue a este enfático anuncio nos causa leve decepción. Porque el concepto de antología, expulsado por el portón, vuelve a entrar por el postigo. Y entra acompañado de una conjetura improbable y de un error cierto: la conjetura, que en el Oráculo volcó Gracián el manuscrito de El Atento; el error, que Gracián no compuso más obras, fuera de las impresas, que los dos tratados de El Atento y El Galante. Concedámosle el mérito de haber puntualizado el número exacto de máximas extraídas de otros impresos del autor, y precisado el modo de condensar en un rasgo los "doze Gracianes". De lo segundo opina: "Lo que hay que entender evidentemente es que en el Oráculo está recogido lo sustancial de todos ellos, los impresos y los manuscritos, o sea las ideas básicas del autor, lo cual es muy cierto" (p. xxvii). En lo que toca a fuentes, después de revistar las reminiscencias apuntadas por sus predecesores hasta un total de 78 , las reduce a 72 , muy pocas literales, unas 5o sumamente elaboradas. Tras el recuento objetivo, viene la adivinación: si más de tres cuartas partes del Oráculo no proceden de fuente precisa que nos sea conocida, ¿̇será mucho suponer que en él entró íntegro o en gran parte el manuscrito de Avisos al varón atento? (p. xxviii).

Me temo que el viejo proverbio "time hominem unius libri" sea 
verdad en más de un sentido. Acabamos por absorbernos en el autor favorito y figurarnos que sabemos cuanto hay que saber sobre él. Romera-Navarro, como si su tenaz dedicación hubiese aclarado los misterios y enigmas que envuelven la vida y obra del jesuita, interpreta así el pasaje de los "doze Gracianes" (p. xxv):

Si doze no está dicho en número redondo, aproximado, entonces habrán de ser contados tales libros como sigue: El Héroe (1637); El Político (1640); El Arte de ingenio (1642); El Discreto (1646); Agudeza y arte de ingenio (1648), refundición notablemente ampliada de aquel tercer libro que estaba ya manuscrita; Avisos al varón atento, que nunca llegó a imprimirse, pero que Gracián iba escribiendo al mismo tiempo que El Discreto...; El Criticón, contando sus tres partes publicadas luego separadamente $\left(16_{5}{ }^{1-53-57)}\right.$ como tres libros, y que estarían ya en todo o en parte manuscritos; El Comulgatorio, no impreso hasta 1655 ; El Galante... y extrañamente el Oráculo mismo.

Arriesgado parece incluir El Comulgatorio, pero sólo extrañeza puede causar el contar por triplicado El Criticón y el considerar el Oráculo como extracto y antología de si mismo. Resignémonos a aceptar lisa y llanamente la aserción de que Gracián tenía empezados, adelantados o terminados doce tratados de los que algunos ni de nombre nos son conocidos. No hay argumento más sujeto a quiebras que el argumentum a silentio, ya que basta un solo testimonio para derribar un castillo de hipótesis. El testimonio lo he encontrado en una pieza preliminar de la edición princeps de El Politico, la cual nos informa de que Gracián el año de 1640 estaba preparando para la imprenta una obra denominada Ministro real.

En una subasta portuguesa reciente logré adquirir la edición princeps de El Politico, reliquia de extrema rareza, acaso ejemplar único. Cuando en 1953 la Institución Fernando el Católico, hijuela del C. S. I. C. en Zaragoza, reprodujo en facsímil la obrita, tuvo que echar mano de la segunda impresión (El Politico D. Fernando el Católico de Lorenço Gracián. Que publica Don Vincencio Iuan de Lastanosa. Con licencia en Huesca: Por Iuan Nogues. Año 1646). El prologuista Francisco Yndurain aseguraba: "La primera, anterior a 1640 , no nos ha llegado, aunque tenemos testimonio cierto de que la hubo". La impresión de Huesca, tal vez destinada a circular privadamente, carece de preliminares: en nuestro ejemplar ocupan 7 folios. La portada reza: EL POLITICO / D. FERNANDO EL CATOLICO / DE / LORENZO GRACIAN / AL EX ${ }^{\text {Mo }}$ SEÑOR / Don Francisco María, Carafa, Castrio- / to, y Gonzaga, Duque de Nochera, / [sigue una lista de títulos] / Con Licencia, y Priyilegio. / En Zaragoza, por Diego Dormer / Año M.DC. XL. Los preliminares son: Censura del Dotor Pedro de Abella; -Licencia, 12 noviembre 1640; -Erratas; -Censura del Dotor Ivan Francisco Andres de Vztarroz; -Suma del privilegio (por diez años, fechado a 27 de noviembre de 1640 ); - Texto.

El texto -tras la portada y 7 hojas sin numerar- empieza con la signatura $\mathrm{Ai}$; comprende 222 páginas numeradas al igual de la edición oscense, que lo reproduce bastante fielmente a página aunque no siempre a renglón. El tamaño de la caja es $7^{8}$ por $5^{6} \mathrm{~mm}$. El ejemplar, 
bien conservado, procede de los jesuítas de París según indicación manuscrita de la época: "Collegii Paris Societ. Jesu".

Vamos a copiar íntegra la

Censura del Dotor Ivan Francisco Andres de Vztarroz. De orden del Excelentissimo Señor Duque de Nochera, Principe de Seila, Lugarteniente y Capitán General en los Reynos de Aragon y Navarra

Eterniza las memorias (Señor Excelentissimo) del glorioso Rey Don Fernando II. de Aragon y V. de Castilla, este breve Diseño de sus heroicas acciones, coloriendo [sic] artificiosamente Lorenço Gracian con el ingenioso pincel de su pluma, no solo su Idea, pero dibuja en diferentes lejos y distancias las virtudes y deliquios de otros Principes. Gloriarse puede la Villa de Sos por auer nacido en ella, en la antigua Casa de los Sadas, Principe tan singular, cuya dicha pudieran embidiar muchas Ciudades.

No puedo dexar de darle muchas gracias al Autor deste erudito trabajo, por auer sabido escoger Mecenas de tan excelentes y abentajadas partes, cuya prudencia se acredita con acciones propias: publíquelo la peregrinación que V. Excelencia hizo por Francia, Flandes, Alemania, Inglaterra, Polonia y otras prouincias, dexando sus esclarecidos lares, por boluer a ellos rico de experiencias, y glorioso de trofeos, aviendo vertido en Argentina en defensa de la Religion Catholica mucha sangre de sus generosas venas.

Diga la Militar disciplina quantas vezes vio a V. Excelencia acaudillar numerosos exercitos, y con el valeroso denuedo que reconocio de orden del Señor Infante Cardenal las fortificaciones y quarteles de Veymar para descubrir sus designios, y auiendolo executado dichosamente como platico soldado predixo las intenciones del enemigo, que a no auerlos preuisto su marcial viueza pudieran aver causado algun desorden. Hable Viena Corte de los Emperadores de Alemania, las vezes que vio V. Excelencia Embaxador eloquente en sus estrados y doseles. Pero yo solamente dire que deve V. Excelencia ennoblecer con su protección el Politico de Lorenzo Gracian por dos causas. La primera porque la nobilisima Casa de V. Ex. sabe defender los Serenissimos Reyes de Aragon, no lo callaran las historias, ni son hazañas que las pueda obscurecer el oluido, pues no ay quien ignore la prudencia y el valor de los dos famosos Caualleros Don Antonio Carafa y D. Diomedes su hijo, por cuyo medio recobró el Magnanimo Rey D. Alonso el opulento Reyno de Napoles, y V. Ex. como sucessor de tan esclarecidos Principes defendera esta obra. La segunda causa por la qual hallara tutelar Asylo el Autor deste desvelo, es por ser V. Ex. protector de los varones doctos, heredando esta inclinación con la sangre, pues sabe Italia que el Palacio del Excelentissimo Señor Don Fernando Carafa padre de V. Ex. fue Museo de eruditos y celebres ingenios. Merece el Politico que V. Ex. le haga la honra que al Heroe, y la que previene al Ministro Real, dandole la licencia que suplica por no hallarse en este libro cosa que ofenda las buenas costumbres, ni las Regalias de su Magestad. Assi lo siento, en Çaragoça a XXI. de Noviembre Año M.DC.XL.

El D. Iuan Francisco Andres de Vztarroz

E1 amigo de Gracián nos revela así que éste traía entre manos un libro titulado Ministro real, tan adelantado que Uztarroz lo anunciaba como de próxima aparición. La portada y preliminares suministran un 
segundo e inesperado dato: que $E l$ Politico, a pesar de las afirmaciones de Latasa (seguido por la tropa de gracianistas), no fue publicado por Lastanosa, el cual sólo tomó la iniciativa en la segunda impresión.

Ya hemos descubierto el escueto título de uno de los tratados perdidos, de uno de los "doze Gracianes" puestos a contribución para componer el Oráculo manual. Quedan interiormente formuladas y sin posible respuesta las inevitables cuestiones: ¿Por qué no publicó $-\mathrm{y}$ acaso ni siquiera acabó- el libro planeado? ¿Influyeron en su renuncia las sublevaciones de Cataluña y Portugal, el cuarteamiento del Imperio español, el descrédito de los ministros reales? ¿Qué fragmentos han sido utilizados para el mosaico del Oráculo manual? La vida y la obra de Gracián abundan en laberintos sin hilo documental que nos guíe a solución segura.

Eugenio Asensio

Lisboa.

\section{MÁS SOBRE MONTALVO Y MENÉNDEZ PELAYO}

$\mathrm{Al}$ aparecer $\mathrm{mi}$ artículo sobre "Montalvo y Menéndez Pelayo" (NRFH, 11, 366-985), los doctores Julio Torri y Emilio Uranga, catedráticos de la Facultad de Filosofía y Letras de la Universidad de México, me dieron noticia verbal de las referencias a Montalvo que figuran en el Epistolario de Menéndez Pelayo y Rodriguez Marin (Madrid, 1935), no utilizadas por mí. Se trata del juicio de Menéndez Pelayo sobre los Capitulos que se le olvidaron a Cervantes, obra póstuma de Montalvo excluida del examen cronológico de mi trabajo, que en realidad no altera mis conclusiones, antes las refuerza.

En carta fechada en "Sevilla, 3 de noviembre de 1896 ", don Francisco Rodríguez Marín propuso la cuestión: "He leído el decantadísimo libro de Montalvo. Cuando esos capítulos se le olvidaron a Cervantes, paréceme que no durmió, sino que estuvo muy despierto. ¿No cree usted lo mismo?" (p. 73). Don Marcelino contestó desde "Santander, 8 de enero de 1897 ", lo siguiente: "Veo que el librote del americano Montalvo le hizo a usted la misma impresión que a mí. Confieso que no pude acabar su lectura, ¡Qué fárrago tan insulso! IQué falta de gracia y de amenidad! Pero ¿qué podía esperarse de un hombre que tiene la temeridad de completar a Cervantes, y aun de enmendarle la plana?" (p. 78 ).

Por lo pronto, es notoria la injusticia de atribuir a Montalvo semejante intención; Montalvo, quizá no con humildad, pero sí consciente de sus limitaciones, convino que su obra fuera sólo un "ensayo de imitación de un libro inimitable", como reza la portada ${ }^{1}$. El despectivo "librote" con que se inicia la andanada se explica como un arranque

1 Capitulos que se le olvidaron a Cervantes. Ensayo de imitación de un libro inimitable. Obra póstuma de Juan Montalvo. Imprenta de P. Jacquin, Besanzón 1895 . Menéndez Pelayo conservó un ejemplar de la segunda edición (Montaner y Simón, Barcelona, 1898 ), con dedicatoria de los editores; signatura $2595 / 4175$, en su Biblioteca, Santander. El propio Montalvo, al incluir entre los Siete tratados, en 1882, el Buscapié de los Capitulos, ya se curaba en salud de los posibles cargos que se le harían a la publicación de la obra: "Mas cuando estamos señalando los defectos del vecino y fiscalizando su manera de escribir, no sabemos si nosotros mismos vamos cayendo en otros peores; y así, por no volvernos culpables de fatuidad sobre la nota de ignorantes, hemos preferido la culpa del atrevimiento, bautizándola con el nom- 